\title{
Part time work: one year's job share in Bristol
}

\author{
SHEILA MONTGOMERY，TONY O’REILLY，T L CHAMBERS
}

For those doctors who decide to work part time after several years of full time experience, clinical assistant sessions are invaluable for keeping knowledge at a reasonable level. But for those who are not fully trained and who need to work part time the clinical assistant posts are often not helpful for general learning; indeed, they are not considered as training experience. Many junior doctors have had to branch off into seeking sessions in posts that have variable responsibility and little chance of promotion. There is thus a demand for part time posts at the trainee senior house officer level, and the only feasible way of undertaking them is by job sharing.

Two of us are junior doctors who have to work part time for domestic reasons but are not yet fully trained. We both qualified in Bristol in June 1978. After house officer jobs one of us (SM) did six months as a senior house officer in casualty, three months as a senior house officer in psychiatry (both full time), and then two years as a clinical assistant in psychiatry (four sessions a week). TO'R did a six month post in medicine and surgery in France, then 18 months also doing clinical assistant sessions in psychiatry (six sessions a week). Both of us were glad to have had the clinical assistant posts, though we did feel that we had shunted ourselves into a career branch line. We wanted to get more experience to train for general practice but were resigned to the idea that this would have to wait a few years until family commitments had lightened. We also realised that with increasing competition for jobs few consultants would be keen to employ older applicants whose only recent experience was a few years in psychiatry.

In 1981 a senior house officer post in paediatrics was advertised as being open to applicants who wanted to share the post. The year's rotation consisted of three stages of four months: the first stage was in acute general paediatrics with on call duty at Southmead Hospital; the second stage included paediatric cover in the paediatric, neurology and neurosurgery, and plastic surgery and burns wards at Frenchay Hospital, together with some general paediatric outpatient work; the last stage was in community paediatrics in the Southmead Health Authority.

Having just completed the post, we think that our experience should be documented and we have done this under the following headings: organisation of clinical work, expected problems and unexpected problems; advantages for us, for the other staff, and for the patients and their parents; and administrative arrangements.

\section{Bristol BS7 9BA}

SHEILA MONTGOMERY, $\mathrm{MB}$, CHB, senior house officer in paediatrics TONY O'REILLY, MB, CHB, senior house officer in paediatrics

\section{Children's Department, Southmead General Hospital, Westbury- on-Trym, Bristol BS10 5NB}

T L CHAMBERS, MB, FRCP, consultant paediatrician

Correspondence to: Dr T O'Reilly, 14 Hurlingham Road, St Andrews, Bristol BS7 9BA.

\section{Organisation of clinical work}

We obviously had to satisfy the interviewing committee that we were capable of thorough planning. We prepared a carefully structured timetable to ensure that continuity of care and equal division of labour between us both were maintained. We were also determined to remain flexible about our work shifts should the need arise-for example, working the afternoon before a $\infty_{\infty}^{\infty}$ night on call and the morning after, and ensuring that the one os of us who was on call the night before a major ward round if would also cover that ward round. Straightforward discharge summaries were divided on a numerical basis, but summaries $\vec{N}$ requiring more thought and information were usually done by the doctor who covered the original admission. Good com- $\frac{\text { a }}{-}$ munication between us was essential, and we made a point of $\omega$ having detailed handover periods at lunchtime, as well as $z$ frequent telephone calls. As we both occupied one post we had to arrange to take our holidays at the same time, and advance planning avoided any problems.

\section{Expected problems}

The main worries expressed at the interview concerned the continuity of care, acceptance by patients and staff, and doubts

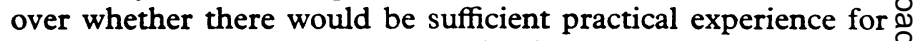
a training post. We hoped to maintain continuity of care and $\mathbb{D}$ exchange of information by our handover periods, and by introducing our opposite partner to the patients and their $\frac{0}{3}$ parents. Acceptance was on the whole easier for the patients than for the staff. The junior medical staff were dubious at first about the efficiency of the arrangements, fearing that they would be called on to provide extra cover. We think that their doubts were soon allayed, and at the end of each stage they and the nursing staff with whom we worked were all satisfied with our performance. Whether the post gave us enough practical experience is debatable: it would not have made us ready to $ᄋ$ apply for more senior paediatric posts, but that was not our aim. Though we had less time for practical training, the job gave us 음 good overall paediatric experience, and despite being on the $N$ wards less than the full time senior house officer we still had the same caseload and saw the same variety of conditions.

\section{Unexpected problems}

Unexpected problems were twofold: money and workload We often stayed longer than planned, and SM, who has pre- $\frac{\mathbb{D}}{\mathscr{D}}$ school children, was obliged to spend more money on child $\stackrel{\oplus}{?}$

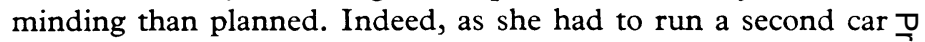
she was effectively paying to go to work. We put in a lot more $\stackrel{P}{\mathbb{P}}$ hours than the expected "half time," sometimes to ensure a $\stackrel{\mathbb{D}}{\square}$ satisfactory handover during busy periods, sometimes to see a $\mathbb{Q}$ particular case through, and occasionally to help out other colleagues. The time spent at our handovers usually meant that 8 we had to miss the lunchtime hospital postgraduate meetings. Also, we nearly always missed the weekly postgraduate paediatric lectures; while the on call senior house officer remained 
on the wards the others went to the lectures, and we thought that we could not afford to go while we were on the wards for half the time.

The partner of one of us also worked with his own on call rota, and this caused enormous pressures at home. The couple had little time together, and those moments they did have with each other were often to hand over the children. There is thus another proviso for job sharing-that of commitment and support from the other parent, plus fail safe child minding. The provision of a crêche could reduce this pressure and allow meetings between working parents to be less hectic. These difficulties were not the lot of typical senior house officers, who are usually childless or without the main responsibilities for their children. We also sensed that a scapegoat factor was at work: mistakes made during our work were sometimes attributed to the fact that we shared the post, and in some respects our colleagues' similar mistakes seemed to come under less scrutiny.

\section{Advantages}

The main advantage for us was that of obtaining a training post that would otherwise be denied to people with family responsibilities. There were several advantages to overall patient care. Our frequent meetings often gave a fresh approach to particular problems, and when one of us was tired after a night on call it was satisfying to be relieved by someone ready to finish the remaining chores. Because of our flexibility with the work shifts, we could always cover each other's minor illnesses so that during last year's influenza epidemic, when all our colleagues were absent for short periods, we managed to fill our post between us. Contrary to our expectations parents and the children liked the choice of two permanent doctors. At times parents would find it easier to confide in one of us, although they knew that this information would be shared. We could also ask extra questions that the other partner might not have thought about at the admitting interview, yet that might seem to be relevant on discussion at our handover.

\section{Administrative arrangements}

The main administrative difficulty that we foresaw was financial: two lots of national insurance payments and two lots of superannuation payments. With the pay as you earn system, however, deductions are now made as a straightforward percentage. This system, called the "on cost" system, deducts superannuation, national insurance, and graduated pensions at a standard $18 \%$, so that the cost to the hospital is the same for two job sharers as it is for one person.

For the personnel department the main problems were selection and how to cope with the scheme if one member became seriously ill or did not meet the standards required in the post. It would be almost impossible to select from a list of applicants two people unknown to each other who might be able to work together. The only feasible way is for two people to decide that they could work together and put in a joint application. From our point of view we think it important to say that the two of us who did the shared post were not close friends, and had met again by chance. Our compatibility was mostly due to our overriding commitment to make sure that the job worked; this itself created a climate of mutual respect and help.

If one half of the duo had to leave the other member would still be under contract and the problem of finding someone to fill half a job would arise. In agreeing to run such a scheme the personnel department took the risk of such problems: would the new locum have the same commitment; could the new pair work together and cooperate as well? We cannot answer those questions but hope that the increasing demand for part time work will give a bigger pool of people eager to try job sharing.

\section{Consultant's view}

Mindful of the difficulties facing doctors with domestic commitments, the health authority advertised the senior house officer post as being available for part timers to share. At the first interview TO'R and another part timer were not the first choice, but the appointments committee was impressed by the proposed arrangements for sharing and four months later SM and TO'R were the preferred candidates for the post.

During the first four months of the rotation the scheme worked well, and by all the customary criteria that one uses to assess house physicians the job sharers performed well. Some lapses in communication occurred-but no more than with single post holders. Once their medical and nursing colleagues (not to mention switchboard operators) had become accustomed to the arrangements they ran smoothly. The second four months were probably the least successful: the post is more difficult, it meant working for many different consultants, and there were reservations about continuity and communications on both sides. The final four months were in community child health and job sharing suited its sessional pattern of work. Is this an indication of future employment patterns for these doctors?

Some potential difficulties (not experienced) were:

(a) If one partner was ill, lazy, or incompetent how might he or she be replaced? Would the more competent partner be overwhelmed with work left by a less diligent colleague?

(b) If this arrangement became more common would the motivation of the partners be as high and thus continuity and communication be maintained ?

(c) Was the experience sufficient? The two job sharers worked for two months in general paediatrics: if this was during a quiet summer would they achieve clinical and technical proficiency?

There were some advantages over the single post holders: both job sharers were anxious to make the unique arrangement work and thus probably worked $10-20 \%$ more than half time; and one was often available to act as a locum tenens for another house physician on leave. Perhaps their greatest contribution to the firm, however, was enthusiasm and their wide experience outside medicine, particularly when dealing with chronic illness or handicap-such qualities are not invariably found at this level but are important for the morale of a department.

\section{Conclusion}

We found that the scheme worked well overall. It was hard work, and financially unrewarding for one of us, but enjoyable and challenging. The scheme prompted interest among the other junior doctors, most of whom were encouraging, though others were non-committal and gave the impression that we were second class doctors. Whatever they thought we hope this article shows that job sharing is not an easy option. With the increasing numbers of women doctors, the current regulations that general practitioners must have two years of hospital posts, and the rise in medical unemployment, job sharing schemes are an apposite development. Such schemes can work efficiently alongside full time posts and are not to be seen as charitable or token posts. Other centres-for example, Manchester and Oxford-have also shown that job sharing is a viable alternative. The challenge is there, and we hope that more consultants will take it and see that job sharing can provide a valuable service to their teams.

We are grateful to the consultants who agreed to the experimentDr Brent Taylor and Dr B D Speidel at Southmead Hospital, and Dr D Burman and Dr W Schutt; to the neurosurgical and plastic surgery teams at Frenchay Hospital; to Dr J Price, senior clinical medical officer, Southmead Health Authority; and to Miss M Wilcox of Southmead Hospital personnel department for her support and advice. 
harmed your government's image. . . . We hope that you will convey to your president the need for the speedy release of these prisoners."

\section{Intimate body searches for drugs: police Bill amended}

Government amendments to the Police and Criminal Evidence Bill passed in the House of Lords on 18 October and agreed in the House of Commons on 25 October authorise nurses as well as doctors to undertake an intimate body search and to search for class A drugs in certain circumstances. The Bill does not oblige a doctor or nurse to undertake a search on the authorisation of a senior police officer; it provides the authority in law for a search to be made.

In the BMA's view there is no objection to a doctor carrying out an intimate body search where the purpose is to remove an object which is of immediate danger to the life or personal safety of the suspect or of those people responsible for the suspect's custody and supervision. The association does not, however, agree with the government's contention that there should be a clear provision in the Bill for an intimate search to be carried out when a dealer or carrier is suspected, on reasonable grounds, of internally concealing drugs, particularly heroin. The list of class A drugs includes over 85 substances, and the BMA sees no reason for the provisions in the Bill to be as extensive as the government has decided.

The Bill was due to receive the Royal Assent on 31 October. The government has made it clear, however, that there is no power for police officers to carry out intimate searches for drugs. Such searches must be carried out by a police surgeon or another qualified person, such as a medical practitione or a registered nurse or midwife. If neither doctor nor a nurse is available a search will not be made.

\section{Medical profession appeals for Turkish prisoners}

The chairman of the BMA council, Dr John Marks, and four other senior members of the profession have signed a letter to the Turkish ambassador in the United Kingdom asking about the justification for the severe sentences imposed in November 1983 on members of the Turkish Peace Association. The signatories, Sir Raymond Hoffenberg, president of the Royal College of Physicians; Professor Sir Martin Roth, professor of psychiatry, University of Cambridge; Professor Bernard Knight, professor of forensic pathology, University of Wales; and Professor John $\mathrm{H}$ Humphrey, professor emeritus of the Royal Postgraduate Medical School, London, are particularly concerned about the president of the Turkish Medical Association, Dr Erdal Atabek, and the professor of medicine in the University of Istanbul, Professor Mertin Ozek. The letter states: "It has not, to our knowledge or according to the indictment, been proved that they have taken part in any secret or overt activity which would be illegal in Britain or in any other NATO country. . . . It is reported that the prisoners remain under degrading conditions of detention. ... The lengthy trial and severe sentences have

\section{Section 63 funding}

At its last meeting on 18 October the General Medical Services Committee was told that the working party set up between the committee and the Department of Health and Social Security to consider the allocation and distribution of section 63 funds was unlikely to report until November. The chairman, Dr M J Wilson, said that the negotiators were unwilling to enter into negotiations over further interim arrangements. The DHSS was not prepared to remove the temporary restrictions banning the zero rating of courses and allowing attendance at courses which mean a journey of over 100 miles (one way) only in exceptional circumstances and with the prior arrangement of the family practitioner committee on the advice of the local medical committee.

\section{Pharmacists back generic substitution}

The Pharmaceutical Services Negotiating Committee, which is a statutory body representing the interests of nearly 10000 pharmacists in England and Wales, has given its backing to generic substitution on National Health Service prescriptions provided that there are safeguards. The safeguards would be that substitution would be allowed only where bioavailability and therapeutic equivalence had been proved and the substituted product came from an approved list of manu-

\section{GMSC/RCGP joint computing policy group}

\section{3 report} accompanied by a rapidly increasing interest in group's function is to advise its parent bodies, and this is undertaken by reporting to the liaison committee of the Royal College of General Practitioners and the General Medical Services Committee. The group expressed to that committee its concern that it may not be able to achieve maximum impact on the orderly development of general practice computing as a result of its somewhat indirect channel of communication. The liaison committee, however, decided that the present arrangements should stand for the time being.

A paper was drafted which considered not only the special requirement of computerised systems, but also the need for tightening the facturers.

The third year of the group's activity has been computers by general practitioners. The security of manual records. The paper has been passed to the parent bodies for further con- $\mathbb{D}$ sideration.

The group expressed some of its anxieties about the Data Protection Bill. The Bill fell, of course, as a result of the general election, but the group will continue to monitor and $\Phi$ advise on the newly introduced and slightly modified replacement Bill.

The contracts offered by computer suppliers do not always recognise the special circum- $\overrightarrow{\vec{c}}$ stances of the general practitioner whose technical resources are usually nil and whose financial resources are small. The technical working party has, therefore, drawn up a model contract which has been approved by the $\mathbb{\mathbb { D }}$ group and has now been passed for legal scrutiny.

At present virtually all computer generated $\overrightarrow{0}$ prescriptions are produced in batches to $\vec{A}$ facilitate the issue of repeat prescriptions. The $\vec{\omega}$ group recognised, however, that the printing of individual prescriptions one at a time will soon become desirable. At present such a pro- is cedure entails the wasting of alternate pre- $\subseteq$ scription forms in order to obtain the necessary of alignment within the printer. The group has, of therefore, drawn up simple recommendations (which have now been accepted by the parent $\vec{N}$ bodies) that entail the provision of computer $f$ suppliers of printers and software which will avoid this wastage.

\section{Testing general practitioner systems}

The Department of Health and Social $\bar{\oplus}$ Security has funded a feasibility study into the + methods of testing of general practice systems. The project has been undertaken under the joint supervision of the DHSS and the group. The technical appraisal of the system has been made by the National Computing Centre, while the evaluation of the systems as they are $\triangle$ used in practice has been undertaken by the $\vec{\overrightarrow{ }}$ department of postgraduate education in general practice in the University of Exeter under the supervision of $\mathrm{Dr} \mathrm{R} \mathrm{V} \mathrm{H}$ Jones (former chairman of the group). This is solely a feasibility study. Only if it is successful will attempts be made to set up a definitive testing procedure to which all suppliers can confidently submit their systems. This project aims to test the computer systems, while the evaluation of the "Micros for GPs" scheme is designed to show the effect of a computer on the practice in which it is installed.

\section{Membership}

Dr Clifford Kay (chairman)

Dr J W Chisholm

Dr Peter Enoch

Dr D J Godfrey

Dr G M Hayes

Dr M J Illingworth

Dr Brian Jarman

Dr R V H Jones

Dr Sam Lucas

Professor D H H Metcalfe

Dr J F Milligan

Dr M P Ryan

Dr G E Singer

Dr Norman Stoddart

Dr R G Turner 